\title{
REVIEW
}

\section{MUC1-C oncoprotein as a target in breast cancer: activation of signaling pathways and therapeutic approaches}

DW Kufe

Mucin 1 (MUC1) is a heterodimeric protein formed by two subunits that is aberrantly overexpressed in human breast cancer and other cancers. Historically, much of the early work on MUC1 focused on the shed mucin subunit. However, more recent studies have been directed at the transmembrane MUC1-C-terminal subunit (MUC1-C) that functions as an oncoprotein. MUC1-C interacts with EGFR (epidermal growth factor receptor), ErbB2 and other receptor tyrosine kinases at the cell membrane and contributes to activation of the PI3K $\rightarrow$ AKT and mitogen-activated protein kinase kinase (MEK) $\rightarrow$ extracellular signal-regulated kinase (ERK) pathways. MUC1-C also localizes to the nucleus where it activates the Wnt/ $\beta$-catenin, signal transducer and activator of transcription (STAT) and NF (nuclear factor)- $\kappa B$ RelA pathways. These findings and the demonstration that MUC1-C is a druggable target have provided the experimental basis for designing agents that block MUC1-C function. Notably, inhibitors of the MUC1-C subunit have been developed that directly block its oncogenic function and induce death of breast cancer cells in vitro and in xenograft models. On the basis of these findings, a first-in-class MUC1-C inhibitor has entered phase I evaluation as a potential agent for the treatment of patients with breast cancers who express this oncoprotein.

Oncogene (2013) 32, 1073-1081; doi:10.1038/onc.2012.158; published online 14 May 2012

Keywords: MUC1; breast cancer; oncoprotein; signaling pathways; targeted agents

\section{INTRODUCTION}

The mucin (MUC) family of high-molecular-weight glycoproteins evolved in metazoans to provide protection for epithelial cell layers that are exposed to the external environment. The human MUC family (MUC1 to MUC21) includes secreted and transmembrane MUCs that afford protection of the epithelia lining the respiratory and gastrointestinal tracts, and lining ducts in organs such as the mammary gland, liver, pancreas and kidneys. The secreted MUCs form a mucous gel that functions as a physical barrier. The transmembrane MUCs contribute to this protective barrier through ectodomains that contain O-glycosylated tandem repeat structures. The transmembrane MUCs also contain single membrane-spanning regions and cytoplasmic domains (CDs) that transduce stress signals to promote growth and survival responses for repair of the epithelial layer. ${ }^{1}$

MUC1 is a transmembrane MUC that was identified by its marked overexpression in human breast cancers as compared with that in normal ductal breast epithelial cells. ${ }^{2}$ MUC1 is translated as a single polypeptide that undergoes autocleavage into two subunits that form a stable non-covalent heterodimeric complex at the cell membrane (Figure 1a). ${ }^{3-5}$ The MUC1-Nterminal subunit (MUC1-N) is the MUC component of the heterodimer containing variable numbers of 20 -amino-acid (aa) tandem repeats that are glycosylated on serine and threonine residues (Figure 1a). ${ }^{6,7}$ The MUC1-C includes a 58-aa extracellular domain, a 28-aa transmembrane domain and a 72-aa CD (Figure 1b).

MUC1-N is tethered to the transmembrane MUC1-C subunit as a complex along the apical borders of normal polarized breast epithelia (Figure 2a). Release of MUC1-N from the cell surface leaves MUC1-C to function as a putative receptor to signal stress to the interior of the cell (Figure 2a). ${ }^{1}$
In breast tumor cells with loss of apical-basal polarity, the MUC1-N/MUC1-C complex is found over the entire cell membrane. $^{2}$ MUC1-N is shed from the surface of carcinoma cells. ${ }^{8}$ In addition, as detected by the CA15-3 assay, MUC1-N is found at increased levels in the plasma of patients with breast cancer. ${ }^{9}$ Loss of apical-basal polarity in breast cancer cells is also associated with interactions between MUC1-C and receptor tyrosine kinases (RTKs), such as EGFR and ErbB2, that are normally positioned at the basal-lateral borders (Figure $2 \mathrm{~b}$ ). The respositioning of MUC1 that occurs with transformation is also associated with substantial upregulation of MUC1 levels, supporting the 'aberrant overexpression' of MUC1 in breast carcinomas (Figure 2c).

\section{Overexpression of MUC1 in breast cancer cells}

MUC1 is aberrantly overexpressed in over $90 \%$ of breast tumors. ${ }^{10-12}$ The overexpression of MUC1 in breast carcinomas is the result, in part, of genetic alterations and dysregulation of transcription. The MUC1 gene is located at chromosome 1q21, a region frequently altered in breast cancer cells. ${ }^{13}$ Amplification of the MUC1 gene has been found in about $40 \%$ of breast cancers and significantly correlates with increases in MUC1 messenger RNA and protein levels. ${ }^{14,15}$ The MUC1 promoter contains binding sites for diverse transcription factors and is activated in breast cancer cells. ${ }^{16-18}$ As described in more detail below, the MUC1-C subunit functions in auto-inductive loops with the STAT1/3 and NF (nuclear factor)- $\kappa B$ RelA transcription factors that confer activation of the MUC1 gene and its overexpression in breast cancer cells. $^{19-21}$

Other studies have demonstrated that MUC1 overexpression is regulated by micro RNAs. miR-125b, which is downregulated in breast cancer cells, interacts with the MUC1 3'UTR and suppresses 
a

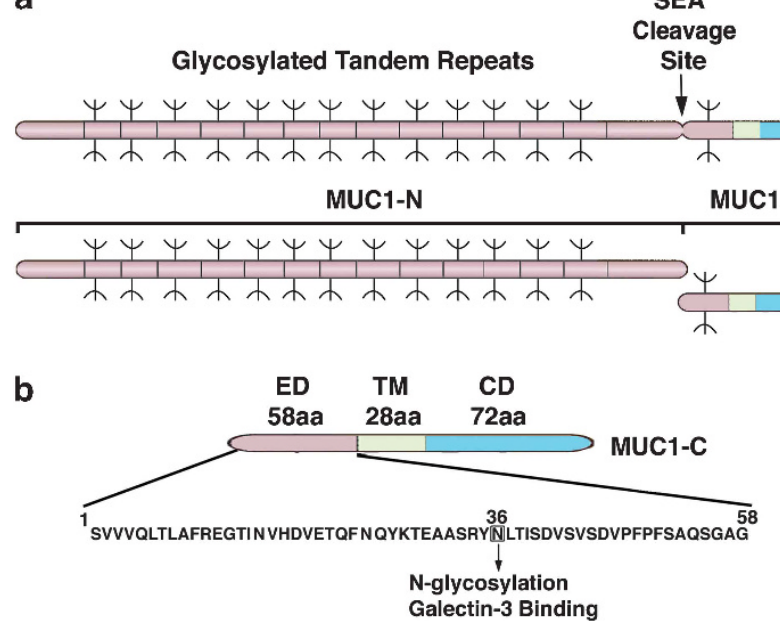

Figure 1. Structure of the MUC1 heterodimer. (a) MUC1 undergoes autoproteolysis at a SEA (sea-urchin sperm protein, enterokinase and agrin) domain to generate two subunits that, in turn, form a stable non-covalent heterodimer. The MUC1-N and MUC1-C nomenclature is used to designate positioning of the subunits after cleavage and to distinguish them from genetic isoforms that are subclassified with Greek characters; for example, $E R \alpha$ and $E R \beta$, the protein kinase $C$ isoenzymes, PDGF receptors and others. (b) The MUC1-C subunit contains a 58-aa extracellular domain that is glycosylated on asparagine at a $\mathrm{N}^{36} \mathrm{LT}$ site. The MUC1-C 72-aa CD interacts with multiple effectors as described below and is sufficient to induce transformation.

MUC1 protein, but not messenger RNA, levels. ${ }^{22}$ miR-145 is also downregulated in breast cancer cells, binds to the MUC1 $3^{\prime}$ UTR and suppresses MUC1 expression. ${ }^{23}$ In addition, miR-1226, which has no other known targets, binds to the MUC1 3'UTR and downregulates MUC1 protein levels. ${ }^{24}$ However, it is not known whether miR-1226 levels are decreased in breast cancer cells as compared with normal mammary epithelial cells.

Other work has further demonstrated that MUC1 translation is markedly upregulated in nonmalignant breast epithelial cells in response to EGF or heregulin stimulation and activation of PI3K $\rightarrow$ AKT signaling. In breast cancer cells, MUC1 translation is constitutively upregulated by the $\mathrm{PI} 3 \mathrm{~K} \rightarrow \mathrm{AKT} \rightarrow \mathrm{mTORC} 1$ pathway and the elF4A RNA helicase. These findings have supported an auto-inductive loop in which $\mathrm{PI} 3 \mathrm{~K} \rightarrow \mathrm{AKT}$ signaling increases translation of the MUC1-C protein and, in turn, MUC1-C contributes to the activation of the $\mathrm{PI} 3 \mathrm{~K} \rightarrow \mathrm{AKT}$ pathway by mechanisms that are described below. In contrast to activating mutations of the PI3K pathway in breast cancer, ${ }^{25}$ there is no evidence that mutants are responsible for the MUC1-C oncogenic function. Indeed, certain mutants of the MUC1-C CD act as dominant negatives of the malignant phenotype when expressed in carcinoma cells. ${ }^{26}$

A model of transformation induced by overexpression of the MUC1-C subunit was developed, which identified activation of gene families involved in oncogenesis and metabolism. ${ }^{27} \mathrm{~A}$ set of experimentally derived MUC1-C-induced genes associated with tumorigenesis was applied to the analysis of a primary breast cancer database $(n=295)$. A 35-gene MUC1-C-induced signature was found to predict highly significant decreases in both diseasefree and overall survival. ${ }^{27} \mathrm{~A}$ set of $38 \mathrm{MUC1-C-induced} \mathrm{genes}$ associated with lipid metabolism was also applied to the analysis of $\mathrm{ER}+$ breast cancer patients treated with tamoxifen. ${ }^{28}$ The results from two individual databases showed that patients with tumors overexpressing MUC1 and the lipid metabolic pathways are at significantly higher risk for recurrence and death. ${ }^{28}$ These findings indicate that overexpression of MUC1-C contributes to
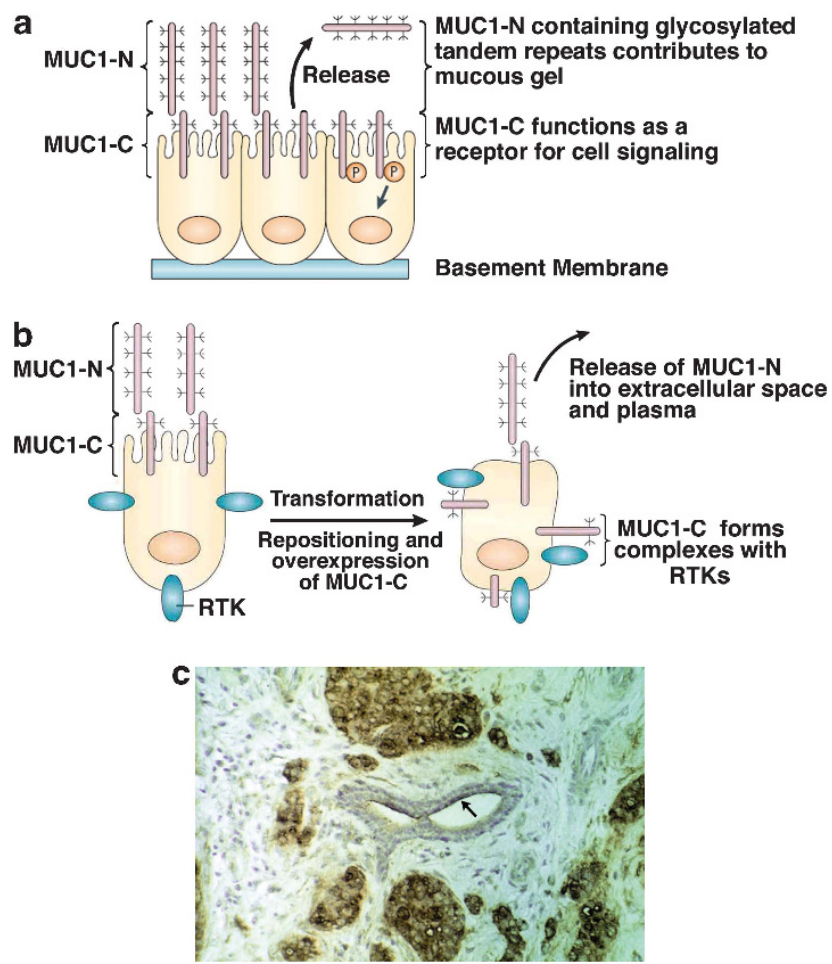

Figure 2. Aberrant localization and overexpression of MUC1-C in breast cancer cells. (a) The MUC1-N/MUC1-C heterodimer is expressed at the apical border of normal mammary epithelial cells. MUC1-N extends beyond the glycocalyx of the epithelial cells and contributes to the protective mucous barrier. With activation of the epithelial stress response and release of MUC1-N from the cell surface into the mucous gel, MUC1-C functions as a second line of defense to signal stress to the interior of the cell and thereby protects against loss of integrity of the epithelial layer. Figure modified from Kufe. ${ }^{1}$ (b) In normal epithelial cells, apical MUC1-C is sequestered from RTKs that localize to the basal-lateral borders. However, with transformation and loss of polarity, MUC1-C is repositioned over the entire cell membrane and forms complexes with RTKs that promote RTK signaling and upregulation of MUC1-C expression. Figure modified from Kufe. ${ }^{1}$ (c) Tissue section containing foci of breast carcinoma cells surrounding normal ducts, which was stained with an anti-MUC1 antibody. Expression of MUC1 along the apical borders of normal ductal epithelial cells (arrow) is in contrast to the increased expression of MUC1 over the entire cell membrane and in the cytoplasm of breast cancer cells. Figure originally published in Gaemers et al. ${ }^{86}$

the regulation of genes that are highly predictive of clinical outcome in breast cancer.

\section{MUC1-C SIGNALING AT THE CELL MEMBRANE}

\section{MUC1-C associates with EGFR}

The MUC1-N/MUC1-C complex is expressed at the apical membrane of polarized epithelial cells. ${ }^{2}$ Conversely, the EGFR localizes to the basolateral membrane in normal polarized epithelia. ${ }^{29}$ With loss of polarity associated with the epithelial stress response $\mathrm{s}^{30}$ or transformation, MUC1-C and EGFR are expressed over the entire cell membrane and are repositioned to form complexes. The MUC1-C extracellular domain is glycosylated on Asp-36, which functions as a binding site for galectin-3, and the formation of galectin-3 bridges that position MUC1-C with EGFR at the cell membrane (Figure 3a). ${ }^{31}$ The MUC1- 
a
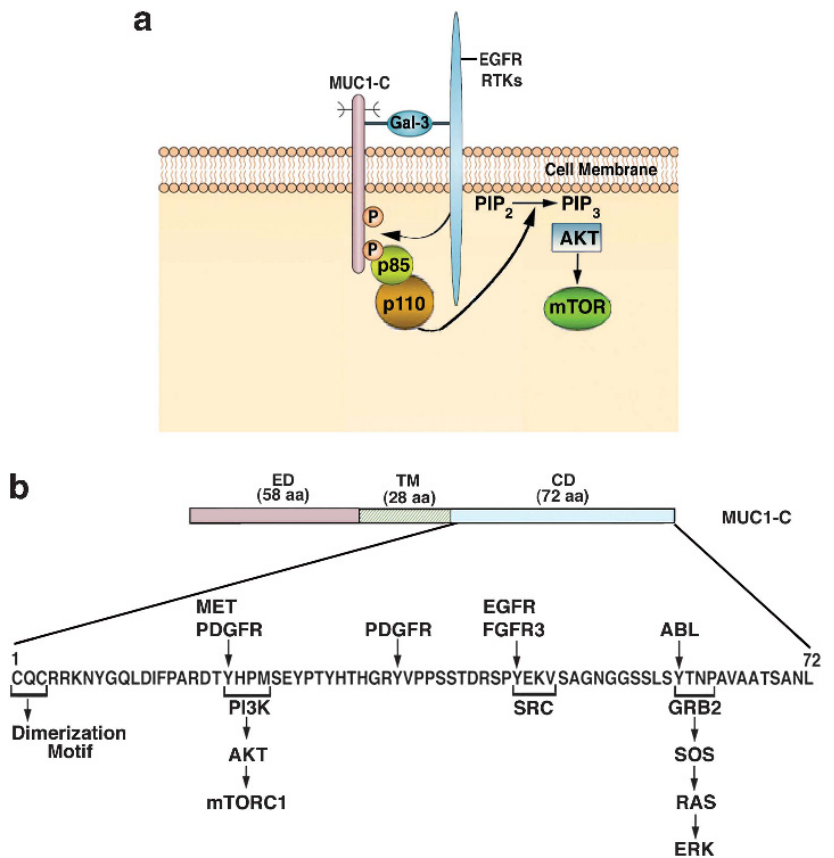

Figure 3. Interaction between MUC1-C and EGFR at the cell membrane. (a) The MUC1-C subunit forms complexes with EGFR at the cell membrane that are mediated extracellularly by galectin-3 bridges. $^{31}$ The MUC1-C CD is phosphorylated by EGFR and other RTKs. In turn, the MUC1-C CD functions as an adaptor for binding of the $\mathrm{PI} 3 \mathrm{~K} \mathrm{SH} 2$ domains and activation of the $\mathrm{PI} 3 \mathrm{~K} \rightarrow$ AKT pathway. ${ }^{46,38}$ (b) The 72-aa MUC1-C CD is phosphorylated by diverse RTKs and non-RTKs, providing binding sites for $\mathrm{SH} 2$ domains in effectors that, in addition to PI3K, ${ }^{46,38}$ include SRC ${ }^{33}$ and GRB2. ${ }^{52}$

C CD also functions as a substrate for EGFR phosphorylation on the $\mathrm{Y}^{46} \mathrm{EKV}$ motif. ${ }^{32}$ In turn, pYEKV functions as a binding site for the SRC homology $2(\mathrm{SH} 2)$ domain. ${ }^{32,33}$

In transgenic mouse models, overexpression of MUC1 is associated with binding to EGFR in mammary glands and the induction of breast tumors. ${ }^{34,35}$ In addition, in an EGFR-dependent whey-acidic protein-TGF $\alpha$ (transforming growth factor) transgenic model, depletion of MUC1 decreases cyclin D1 expression and delays the onset of breast tumors, indicating that MUC1 contributes to EGFR-mediated tumorigenesis. ${ }^{36}$ The interaction between MUC1 and EGFR at the cell membrane has been shown to increase EGFR internalization and recycling. ${ }^{36,37}$ Other work has demonstrated that MUC1-C promotes EGFR-dependent activation of the PI3K $\rightarrow$ AKT pathway ${ }^{38}$ and localization of EGFR to the nucleus. ${ }^{39}$ These findings have established a role for MUC1-C in EGFR turnover at the cell membrane and in EGFR signaling in the cytoplasm and nucleus (Figure 3a).

Interaction between MUC1-C and other RTKs

With regard to other ErbB family members, studies in breast cancer cells have shown that MUC1 associates with ErbB2/HER2 and that this interaction is increased by heregulin stimulation. ${ }^{40}$ MUC1 is also detectable in complexes with ErbB3 and ErbB4 in breast cancer cells ${ }^{40}$ and in mouse mammary glands. ${ }^{34}$ Other studies have shown that MUC1-C associates with fibroblast growth factor receptor 3 (FGFR3), is phosphorylated on Tyr-46 in response to FGFR3 activation and contributes to FGFR3 and SRC signaling (Figure $3 \mathrm{~b}$ ). ${ }^{41}$ MUC1-C also associates with hepatocyte growth factor receptor and is subject to hepatocyte growth factor receptor phosphorylation on Tyr-20 (Figure $3 \mathrm{~b}$ ). ${ }^{42}$ Phosphorylation of the $\mathrm{Y}^{20} \mathrm{HPM}$ motif confers the interaction between MUC1-C and PI3K p85 (Figures 3a and b). ${ }^{38}$ Another example is supported by the demonstration that MUC1-C associates with the platelet-derived growth factor receptor $\beta$, which phosphorylates the MUC1-C CD on Tyr-20 and Tyr-35, and enhances MUC1-mediated invasion (Figure 3b). ${ }^{43}$

These findings have collectively supported a role for MUC1-C in interactions with diverse RTKs at the cell membrane and in their downstream signaling pathways.

MUC1-C activates the PI3K $\rightarrow$ AKT pathway

The PI3K pathway is of importance to the growth, survival and metabolism of cancer cells. ${ }^{44}$ PI3Ks transduce signals from RTKs and G-protein coupled receptors by generating phospholipids that confer activation of the serine-threonine protein kinase AKT and other effectors. ${ }^{45}$ The PI3K p85 regulatory subunit contains $\mathrm{SH} 2$ domains that interact with pYXXM sequences on activated RTKs. In turn, PI3K p85-mediated inhibition of the PI3K p110 catalytic subunit is repressed and p110 generates phosphatidylinositol-3,4,5-triphosphate necessary for recruitment and activation of AKT at the cell membrane.

MUC1-C functions as a docking site for activation of PI3K $\rightarrow$ AKT signaling (Figure 3b). Initial studies demonstrated that MUC1induced transformation of rat fibroblasts is associated with increases in p-AKT and that this response is blocked by the PI3K inhibitor LY294002. ${ }^{46}$ Overexpression of MUC1 in DA3 mouse breast cancer cells is also associated with a PI3K-dependent enhancement of growth. ${ }^{47}$ The MUC1-C CD contains a $\mathrm{Y}^{20} \mathrm{HPM}$ motif that, when phosphorylated on tyrosine, functions as a binding site for the PI3K p85 SH2 domains (Figure 3b). In this context, PI3K p85 associates with the MUC1-C CD in vitro and in cells. ${ }^{48,38}$ In addition, mutation of the MUC1-C CD at Tyr-20 blocks binding of PI3K p85 and attenuates MUC1-C-induced activation of the PI3K $\rightarrow$ AKT pathway. ${ }^{48,38}$

The significance of MUC1-C-induced activation of the PI3K $\rightarrow$ AKT pathway is at an early stage of interrogation. One study has shown that overexpression of MUC1-C in breast cancer cells is associated with AKT-mediated increases in glucose uptake and lactate production, indicating that MUC1-C stimulates glycolysis through $\mathrm{PI3K} \rightarrow$ AKT signaling. ${ }^{49}$ Overexpression of MUC1 in NSCLC cells resulted in a marked increase in p-AKT, which was associated with an increase in vascular endothelial growth factor production and proangiogenic activity. ${ }^{50}$ Similar results were obtained in breast cancer cells, supporting a role for MUC1 in promoting vascular endothelial growth factor-mediated angiogenesis by activation of the $\mathrm{PI} 3 \mathrm{~K} \rightarrow$ AKT pathway. ${ }^{51}$ A significant correlation between MUC1 and vascular endothelial growth factor expression was also identified in human breast carcinomas. ${ }^{51}$ The $\mathrm{PI} 3 \mathrm{~K} \rightarrow$ AKT pathway functions in the activation of diverse effectors that promote growth and survival; ${ }^{44,45}$ thus, overexpression of MUC1-C and the upregulation of $\mathrm{PI} 3 \mathrm{~K} \rightarrow \mathrm{AKT}$ signaling in breast cancer cells represents one mechanism by which MUC1-C functions as an oncoprotein.

\section{MUC1-C contributes to activation of the MEK $\rightarrow$ ERK pathway}

The MUC1-C CD contains a $\mathrm{Y}^{60} \mathrm{TNP}$ motif that, when phosphorylated on tyrosine, functions as a binding site for the GRB2 SH2 domain, linking MUC1-C to son-of-sevenless (SOS) and thereby RAS signaling (Figure $3 b) .^{52}$ Involvement of MUC1-C in activation of the RAS $\rightarrow$ $\mathrm{RAF} \rightarrow \mathrm{MEK} \rightarrow$ ERK pathway was supported in part by the demonstration that ERK $1 / 2$ is activated in the mammary glands from MUC1 transgenic mice. ${ }^{34}$ In addition, activation of the MUC1-C $C D$ results in the induction of MEK $\rightarrow$ ERK by a mechanism that is blocked by a dominant-negative RAS mutant and by a MEK inhibitor. ${ }^{53}$ Other studies have shown that overexpression of MUC1 in mouse breast cancer cells ${ }^{47}$ and in human lung cancer cells ${ }^{50}$ results in ERK activation, thus providing experimental models for defining more precisely how MUC1-C contributes to RAS $\rightarrow$ RAF $\rightarrow$ $\mathrm{MEK} \rightarrow$ ERK signaling (Figure $3 \mathrm{~b}$ ). 


\section{INTRACELLULAR LOCALIZATION OF THE MUC1-C SUBUNIT}

MUC1-C is internalized from the cell membrane by clathrinmediated endocytosis by a mechanism involving binding of AP-2 to $\mathrm{Y}^{20} \mathrm{HPM}$ and GRB2 to $\mathrm{PY}^{60}$ TNP sites in the MUC1-C CD (Figure 4). ${ }^{54}$ Recycling of MUC1-C from endosomes back to the cell membrane is conferred by palmitoylation of the MUC1-C CD on cysteines in the cysteine-glutamine-cysteine (CQC) motif. ${ }^{55}$ The overexpression of MUC1-C as found in breast cancer cells is associated with accumulation of MUC1-C in the cytoplasm, probably as a result of retrograde trafficking during endocytosis and return to the endoplasmic reticulum (Figure 4). ${ }^{1}$ In this context, EGFR is a binding partner of MUC1-C at the cell membrane, which is released from the endoplasmic reticulum into the cytosol and then associates with importin- $\beta$ for transport into the nucleus. ${ }^{56}$

Similar to EGFR, MUC1-C interacts with importin- $\beta$ in the cytoplasm and is transported to the nucleus (Figure 4). ${ }^{57}$ Binding of MUC1-C to importin- $\beta$ is dependent on the formation of MUC1-C homodimers. ${ }^{57}$ The MUC1-C CD CQC motif cysteines are necessary and sufficient for MUC1-C dimerization in the cytoplasm of breast cancer cells (Figure 3b). ${ }^{58}$ The MUC1-C CQC motif cysteines also represent a target for blocking nuclear localization and function of this oncogenic subunit. ${ }^{57,58}$

Other studies have shown that cytosolic MUC1-C localizes to the mitochondrial outer membrane, where it blocks apoptosis in response to genotoxic stress (Figure 4). ${ }^{59}$ Stimulation of breast cancer cells with heregulin or fibroblast growth factor is associated with increased localization of MUC1-C to mitochondria by a mechanism involving activation of SRC and transport of MUC1-C by the molecular chaperone HSP70/HSP90 complex. $^{60,41}$ Localization of MUC1-C to mitochondria is also dependent on the formation of MUC1-C homodimers through the CQC motif cysteines in the CD. How MUC1-C blocks activation of the intrinsic apoptotic pathway is a focus of active investigation.

\section{INVOLVEMENT OF MUC1-C IN NUCLEAR SIGNALING}

MUC1-C contributes to activation of the Wnt/ $\beta$-catenin/TCF (T-cell factor)7L2 pathway and cyclin D1 expression

The canonical Wnt signaling pathway is of importance to developmental cell fate and cancer. ${ }^{61}$ The Wnt pathway controls the cytoplasmic abundance of $\beta$-catenin, a key component of the adherens junction of epithelial cells that links cadherin adhesion molecules at the cell surface to the actin cytoskeleton. Cytoplasmic levels of $\beta$-catenin are regulated by glycogen synthase kinase $3 \beta$ (GSK3 $\beta$ ) in a complex with the adenomatous polyposis coli protein and axin. Activation of the Wnt pathway inhibits GSK3 $\beta$ and thereby results in the stabilization of $\beta$-catenin. ${ }^{61}$ In turn, the accumulation of $\beta$-catenin promotes formation of complexes with members of the T-cell factor/ leukocyte-enhancing factor 1 family of transcription factors and the activation of Wnt target genes.

E-cadherin and adenomatous polyposis coli contain SXXXXXSSL sites that are responsible for $\beta$-catenin binding. The observation that the MUC1-C CD also contains a SXXXXXSSL motif led to the demonstration that $\beta$-catenin binds directly to this site (Figure 5, insert), ${ }^{62}$ and thus established the first link between MUC1 and the Wnt pathway. A subsequent study extended these findings by demonstrating that GSK3 $\beta$ binds directly to a STDRSPYEKV site in the MUC1-C CD and phosphorylates the serine residue adjacent to proline (Figure 5, insert). ${ }^{63}$ Phosphorylation of the MUC1-C CD by GSK3 $\beta$ decreased the interaction with $\beta$-catenin and thereby increased the formation of E-cadherin/ $\beta$-catenin complexes. ${ }^{63}$ Further regulation of the interaction between MUC1-C and $\beta$-catenin was established from other studies demonstrating that phosphorylation of the MUC1-C CD by EGFR and SRC at the YEKV site and by protein kinase $C \delta$ at the TDR site increases $\beta$-catenin binding (Figure 5, insert). $32,33,64$

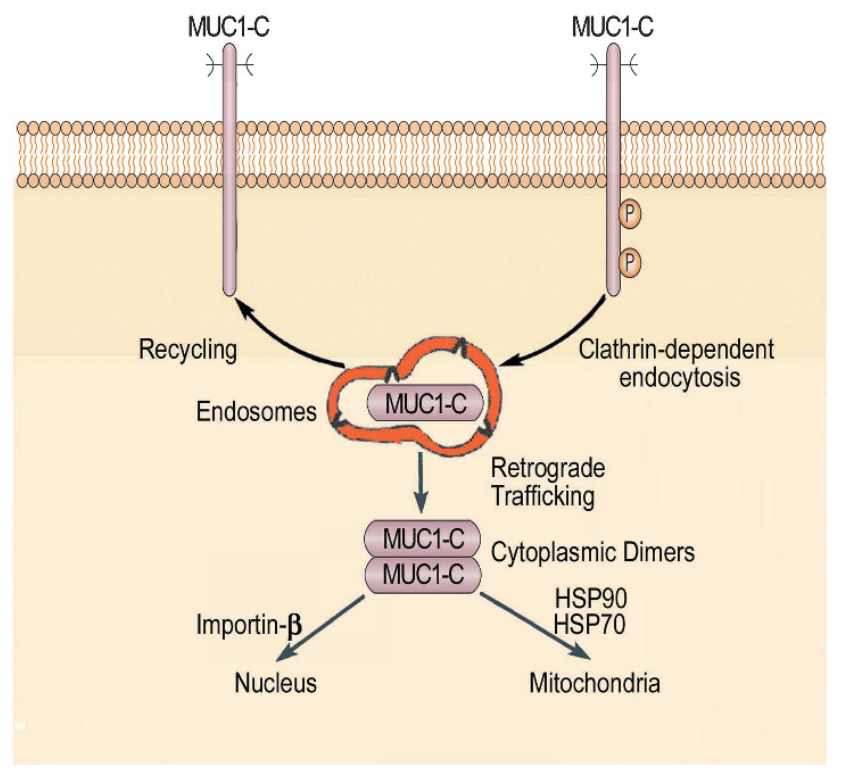

Figure 4. Intracellular cycling of MUC1-C to the nucleus and mitochondria. MUC1-C cycles from the cell membrane to endosomes and then back to the cell membrane. ${ }^{54,55}$ Alternatively, with overexpression in breast cancer cells, MUC1-C accumulates in the cytoplasm, where it forms homodimers that are mediated by the CQC motif in the MUC1-C CD. ${ }^{58}$ MUC1-C dimerization is necessary for transport into the nucleus by importin- $\beta .^{57}$ In the nucleus, MUC1-C associates with transcription factors, such as STAT1/3, NF- $\mathrm{KB}$ RelA and $\mathrm{ER} \alpha$, and contributes to transactivation of their target genes. ${ }^{1}$ MUC1-C is also transported to the mitochondrial outer membrane where it blocks activation of the intrinsic apoptotic pathway. ${ }^{59}$

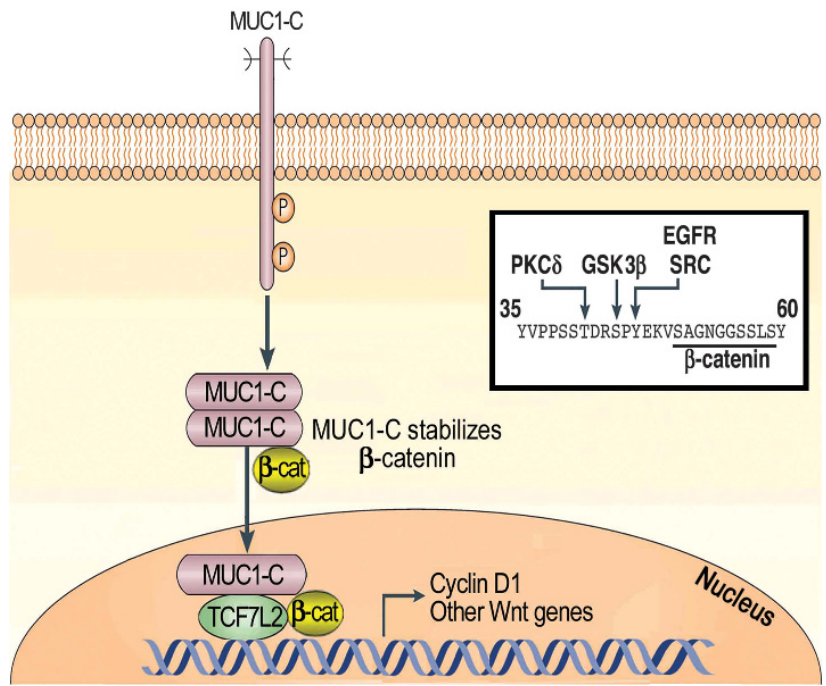

Figure 5. MUC1-C activates the Wnt/ $\beta$-catenin pathway and confers activation of cyclin D1 expression. The MUC1-C CD contains a SAGNGGSSLS motif that binds directly to the $\beta$-catenin Armadillo repeats (insert). ${ }^{62,69} \mathrm{GSK} 3 \beta$, an effector of the Wnt pathway, binds to the upstream STDRSPYEKV site, phosphorylates Ser-44 and decreases binding of MUC1-C to $\beta$-catenin. ${ }^{63,69}$ Phosphorylation of (i) Tyr-46 by EGFR and SRC, and (ii) Thr- 41 by protein kinase $C \delta$, increases the interaction between MUC1-C and $\beta$-catenin (insert). ${ }^{33,32,64}$ Cytoplasmic MUC1-C homodimers bind to $\beta$-catenin and stabilize $\beta$-catenin by blocking GSK3 $\beta$-mediated phosphorylation and degradation of $\beta$-catenin. In the nucleus, MUC1-C forms a complex with $\beta$-catenin and TCF7L2 on the cyclin D1 promoter and coactivates cyclin D1 expression. ${ }^{73}$ 
Subsequent studies in mouse mammary tumor virus (MMTV)Wnt-1 transgenic mice showed that mouse Muc1 forms complexes with $\beta$-catenin at the cell membrane and in the cytoplasm of mammary tumor cells (Figure $5 b$ ). ${ }^{65}$ In addition, MUC1-C/ $\beta$-catenin complexes were detected in the nucleus of MUC1-transformed rat fibroblasts ${ }^{66}$ and MUC1-transfected human pancreatic cancer cell lines. ${ }^{67}$ The functional significance of the nuclear MUC1-C/ $\beta$ catenin interaction is supported by the finding that the MUC1-C CD activates $\beta$-catenin/TCF-mediated transcription and that this effect is abrogated by mutating the EGFR/SRC phosphorylation site that promotes binding of MUC1-C to $\beta$-catenin. ${ }^{68}$ Additional insights were derived from the demonstration that the MUC1-C CD increases $\beta$-catenin abundance in the nucleus by binding to the $\beta$-catenin Armadillo repeats and blocking GSK3 $\beta$-mediated phosphorylation and degradation of $\beta$-catenin. ${ }^{69}$

Disruption of the MUC1-C/ $\beta$-catenin interaction by mutating the SXXXXXSSL site in the MUC1-C CD attenuates MUC1-C-induced anchorage-independent growth and tumorigenicity, indicating that MUC1-C induces transformation, at least in part, by stabilizing $\beta$-catenin and promoting the activation of Wnt target genes. ${ }^{69}$ In support of this model, expression of the MUC1-C CD in the mammary glands of transgenic mice results in marked hyperplasia, increases abundance of $\beta$-catenin in the nucleus and induces activation of the Wnt target genes encoding cyclin D1 and c-Myc. ${ }^{70}$

The work reviewed above established the importance of MUC1$\mathrm{C}$-induced stabilization of $\beta$-catenin in aberrant activation of the canonical Wnt pathway. Nevertheless, a missing piece in the model was how MUC1-C mechanistically activates TCF-mediated transcription. TCF family members bind to Wnt-responsive elements and suppress transcription through interactions with the Groucho repressor. ${ }^{71,72}$ Stabilization of $\beta$-catenin promotes its binding to TCFs and in turn the displacement of Groucho. Thus, MUC1-C-induced stabilization of $\beta$-catenin could be sufficient to activate TCFs and induce transcription. However, recent studies have shown that the MUC1-C CD (i) directly associates with the TCF4/TCF7L2 transcription factor; (ii) blocks the interaction between TCF7L2 and the C-terminal-binding protein, a repressor of TCF7L2-mediated transcription; and (iii) promotes the recruitment of $\beta$-catenin and the coactivator p300 on the cyclin D1 promoter. ${ }^{73}$ These findings have collectively provided support for a pathway in which MUC1-C activates the canonical Wnt pathway by stabilizing $\beta$-catenin and by activating TCF4/TCF7L2mediated transcription of Wnt target genes (Figure 5).

Cyclin D1 is a target gene of the Wnt/B-catenin pathway, which is of importance to mammary tumorigenesis. ${ }^{74}$ Cyclin D1-deficient mice are resistant to induction of mammary cancers induced by erbB2 and ras. ${ }^{75}$ Mice expressing a mutant cyclin D1 ineffective in activating CDK4/6 are also resistant to ErbB2-induced breast cancers. $^{76}$ The cyclin D1 gene is amplified in about $20 \%$ of human breast cancers and cyclin D1 is overexpressed in about 50\%. ${ }^{77-80}$ Interestingly, overexpression of MUC1 and cyclin D1 is significantly linked in diverse human tumors. ${ }^{81}$ In vitro studies have also demonstrated that the MUC1-C CD contributes to the induction of cyclin D1 expression. ${ }^{68,82}$ Activation of cyclin D1 expression is significantly decreased in whey-acidic protein-TGF $\alpha$ (transforming growth factor)/Muc1 $(-/-)$ mice compared with those expressing Muc1. ${ }^{36}$ In addition, expression of the MUC1-C CD in the mammary gland of transgenic mice is associated with pronounced hyperplasia, localization of $\beta$-catenin to the nucleus and induction of cyclin D1 expression. ${ }^{70}$ Other studies have shown that MUC1-C occupies the cyclin D1 promoter with the $\beta$-catenin/TCF7L2 complex and promotes cyclin D1 transcription. ${ }^{73}$ In concert with these results, silencing MUC1-C in breast cancer cells decreases activation of the cyclin D1 promoter and downregulates cyclin D1 expression. ${ }^{73}$ Taken together, these findings have provided compelling support for MUC1-C-induced cyclin D1 expression through activation of the $\beta$-catenin/TCF7L2 pathway in breast cancer cells.
MUC1-C activates STAT1/3 in an auto-inductive loop

STAT family members have been implicated in the link between inflammation and cancer. ${ }^{83}$ STAT1 is activated in the inflammatory response to interferons and is constitutively upregulated in breast and other carcinomas. ${ }^{84}$ The STAT3 transcription factor is an effector of the interleukin-6 (IL-6) inflammatory response. ${ }^{83}$ Activated STAT3 induces transformation and has been detected in various carcinomas. ${ }^{83}$

MUC1 expression in normal breast epithelial cells and breast cancer cells is induced by proinflammatory cytokines, such as interferon- $\gamma$, and activation of STAT1. ${ }^{85}$ Analysis of genes differentially expressed in cells transformed by MUC1 expression further linked MUC1 and STAT1 to a network associated with growth and inflammation. ${ }^{19}$ MUC1-C associates with STAT1 in cells through direct binding of the MUC1-C CD to the STAT1 DNAbinding domain. ${ }^{19}$ The interaction between MUC1-C and STAT1 is induced by interferon stimulation of nonmalignant mammary epithelial cells and is constitutively present in breast cancer cells. The MUC1-C/STAT1 interaction promotes the activation of STAT1 target genes, including MUC1 itself (Figure 6a). ${ }^{19}$ In this regard, the MUC1 promoter contains a STAT-responsive element that contributes to MUC1 overexpression in carcinoma cells. ${ }^{86}$ Of relevance to breast cancer, coexpression of MUC1 and the STAT1 pathway in primary breast tumors is associated with decreased recurrence-free and overall survival. ${ }^{19}$

Other studies have shown that MUC1-C associates with the JAK1/STAT3 complex in breast cancer cells. ${ }^{21}$ The MUC1-C CD interacts directly with JAK1 and the STAT3 DNA-binding domain, supporting a role for MUC1-C in promoting JAK1/STAT3 complexes and JAK1-mediated phosphorylation of STAT3. ${ }^{21}$ In addition, activation of STAT3 in nonmalignant breast epithelial cells by IL-6, IL-10 or IL-22 is dependent on MUC1-C. ${ }^{21}$ As found with STAT1, complexes of MUC1-C/STAT3 are detectable on the promoters of STAT3 target genes, such as cyclin D1 and STAT3. Moreover, MUC1-C and STAT3 are detectable in a complex on the STAT-responsive element in the MUC1 promoter in breast cancer cells. ${ }^{21}$ Thus, MUC1-C and STAT3 function in an auto-inductive loop that may have a role in linking the IL-6-induced inflammatory response to cancer cell survival (Figure 6a).

Further evidence for involvement of MUC1 in inflammatory STAT signaling is provided in an interesting model of Epstein-Barr virus-induced transformation and cellular invasion. ${ }^{87}$ The major Epstein-Barr virus oncoprotein, latent protein 1 (LMP1), induces MUC1 expression through binding of STAT1 and STAT3 to the MUC1 promoter. $^{87}$ In addition, LMP1-induced cell invasiveness is suppressed by silencing MUC1, indicating that the increases in MUC1 expression contribute to the metastasis of Epstein-Barr virus-infected tumor cells. ${ }^{87}$

\section{MUC1-C participates in I $\mathrm{B}$ kinase (IKK)/NF- $\kappa B$ RelA signaling}

The NF- $\kappa B$ transcription factor RelA/p65 localizes to the cytoplasm with members of the $I_{\kappa} B$ family of inhibitor proteins. ${ }^{88}$ Phosphorylation of $I \kappa B \alpha$ by the $I \kappa B$ kinase $(I K K \alpha$, IKK $\beta$, IKK $\gamma$ ) complex induces $I \kappa B \alpha$ degradation and thereby the release of RelA for nuclear translocation. For example, activation of the canonical NF- $\kappa B$ pathway in response to tumor necrosis factoralpha (TNF $\alpha$ ) induces IKK $\beta$-mediated phosphorylation of IKB $\alpha$ with increased localization of RelA to the nucleus. As a result, activation of RelA target genes promotes tumor development through induction of inflammatory responses, growth and survival. ${ }^{88}$

Stimulation of normal human mammary epithelial cells with TNF $\alpha$ has been shown to be associated with binding of RelA to the MUC1 promoter and induction of MUC1 expression. ${ }^{85}$ In addition, mutation of the seven tyrosines in the MUC1-C CD decreases nuclear localization of $\mathrm{NF}-\kappa \mathrm{B}^{89}$ supporting the potential for $a$ MUC1-C/RelA auto-inductive loop. 


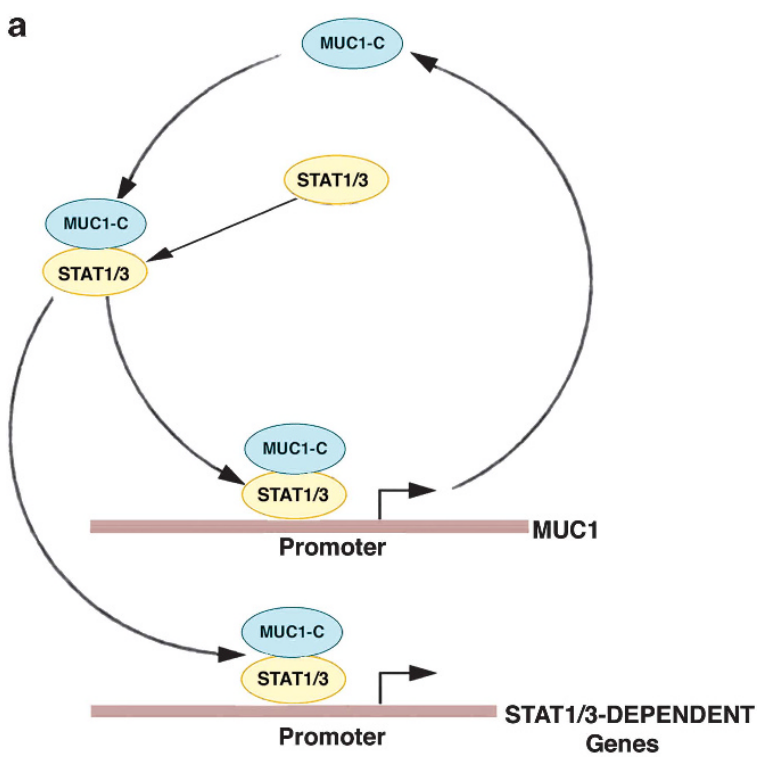

b

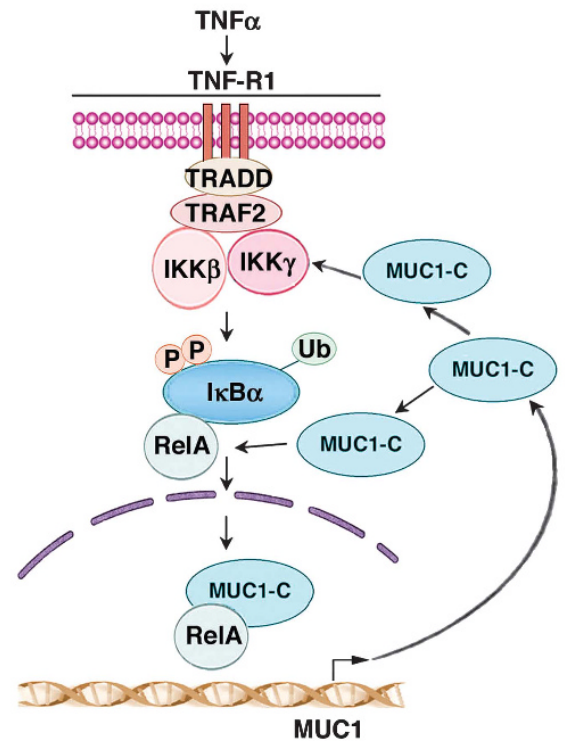

Figure 6. MUC1-C forms complexes with the STAT1/3 and NF- $\kappa B$ RelA transcription factors that in turn activate the MUC1 gene in auto-inductive loops. (a) Schema for a MUC1-C/STAT1/3 autoinductive loop involving activation of MUC1 and other STAT1/3 dependent genes. Figure modified from Khodarev et al., 2010. ${ }^{19}$ (b) Model for the proposed effects of MUC1-C on activation of the NF-KB pathway through interactions with IKK $\beta-I K K \gamma$ and ReIA in an auto-inductive loop. Figure modified from Ahmad et al., 2009. ${ }^{20}$

Studies in breast cancer cells further demonstrated that MUC1-C constitutively associates with the IKK complex through a direct interaction between the MUC1-C CD and IKK $\beta-I K K \gamma .{ }^{90}$ In nonmalignant mammary epithelial cells stimulated with TNF $\alpha$, MUC1-C is recruited to the TNF-receptor 1 complex by a TRADD/ TRAF2-dependent mechanism and interacts with IKK $\beta-I K K \gamma$ (Figure 6b). ${ }^{90}$ The interaction of MUC1-C with IKK $\beta-I K K \gamma$ promotes IKK $\beta$ activation, which results in the phosphorylation and degradation of $I_{\kappa} B \alpha$. These findings have provided support for a model in which MUC1-C is of importance for the activation of IKK $\beta$ and have indicated that overexpression of MUC1-C in breast and other carcinomas promotes sustained induction of the IKK $\beta$ RelA pathway (Figure 6b).

Subsequent studies extended the above findings by demonstrating that MUC1-C also associates with RelA. ${ }^{20}$ The MUC1-C/
RelA interaction was found to be constitutive in breast cancer cells and inducible in TNF $\alpha$-stimulated nonmalignant breast epithelial cells. The MUC1-C CD interacts directly with RelA at the Rel homology domain and, notably, blocks binding of RelA to its inhibitor $I_{\kappa} B \alpha^{20}$ The MUC1-C/RelA complex localizes to the nucleus and occupies the promoters of RelA target genes, such as $B C l-x L$. The MUC1-C/RelA complex was also found to occupy the MUC1 promoter and contribute to RelA-mediated induction of the MUC1 gene. ${ }^{20}$ These results thus provided evidence for an autoinductive loop in which binding of MUC1-C to RelA activates RelA and thereby induction of MUC1-C expression (Figure $6 \mathrm{~b}$ ).

Interaction between MUC1-C and estrogen receptor $\alpha(E R \alpha)$ The MUC1 promoter contains estrogen-responsive elements. ${ }^{91}$ Studies in ER + breast cancer cells have shown that ER $\alpha$ occupies estrogen-responsive elements in the MUC1 promoter and activates MUC1 transcription. $^{91}$ Other work has shown that MUC1-C associates with ER $\alpha$ in breast cancer cells and that this interaction is stimulated by $17 \beta$-estradiol (E2). ${ }^{92}$ The MUC1-C CD binds directly to the $E R \alpha$ DNA-binding domain. The functional significance of the MUC1-C/ER $\alpha$ interaction is supported by the demonstration that MUC1-C stabilizes $\mathrm{ER} \alpha$ by blocking its ubiquitination and degradation. MUC1-C/ER $\alpha$ complexes are detectable on the promoters of estrogen-responsive genes, such as pS2 and cathepsin $D$, and increase recruitment of p160 coactivators. $^{92}$ MUC1-C also stimulates ER $\alpha$-mediated transcription, antagonizes the inhibitory effects of tamoxifen and contributes to E2-induced growth and survival of breast cancer cells. These findings lend support for the contention that MUC1-C is of importance to the activation of ER $\alpha$ function in breast cancers and provide the basis for further studies on the role of MUC1-C in tamoxifen resistance.

\section{TARGETING MUC1 AS A THERAPEUTIC APPROACH}

Monoclonal antibodies (MAbs)

The MUC1-N tandem repeats are highly immunogenic in mice. As such, a number of MAbs have been generated against this subunit and several of these have been developed for clinical evaluation. As a recent example, AS1402 is a humanized immunoglobulin (IgG1) MAb that binds to the MUC1-N tandem repeats and induces antibody-dependent cellular cytotoxicity against MUC1-positive breast cancer cells. ${ }^{93}$ In a Phase I trial, AS1402 levels were achieved that conferred maximal antibody-dependent cellular cytotoxicity activity in vitro. ${ }^{93}$ On the basis of these findings, a Phase II trial of AS1402 in combination with letrozole was performed in patients with advanced or metastatic ER + breast cancer. ${ }^{94}$ The results showed that adding AS1402 to letrazole has no effect on efficacy compared with that obtained with letrazole alone. ${ }^{94}$

As noted above, MUC1-N is shed from the surface of breast cancer cells and is found at increased levels in the plasma of women with metastatic breast cancer. Extracellular pools of MUC1-N thus represent a barrier for the delivery of a MAb to the surface of breast tumor cells for induction of antibody-dependent cellular cytotoxicity. The same argument applies to anti-MUC1-N MAbs developed to deliver a toxin or a radionuclide; the circulating pool of MUC1-N would have to be overcome to target the surface of MUC1-expressing breast tumor cells. In contrast, MUC1-C is not subject to release from the cell surface and is undetectable in plasma. Thus, the 58-aa MUC1-C extracellular domain represents a potential target for the development of MAbs that could more effectively reach the surface of breast tumor cells.

\section{Anti-MUC1 vaccines}

Unlike antibodies, the circulating MUC1-N pool should not pose a barrier for vaccines that induce T-cell responses against MUC1 
peptides that are presented by MHC class I/II molecules on the breast cancer cell surface. Few anti-MUC1 vaccines, however, have advanced to later-stage clinical trials for the treatment of breast cancer. L-BLP25 (Stimuvax; EMD Serono) is a liposome-based vaccine that incorporates a MUC1-N tandem repeat peptide. Stimuvax had been under development for both breast and lung cancer, and is now in a phase III trial for unresectable stage III NSCLC. PANVAC-V (NSC \#727026) is a recombinant vaccinia virusbased vaccine that contains transgenes for MUC1, CEA and three T-cell costimulatory molecules (B7.1, LFA-3 and ICAM-1). ${ }^{95}$ PANVAC-F (NSC \#727027) is a similar vaccine constructed by inserting the same transgenes into a replication-defective fowlpox virus. ${ }^{95}$ In a recently reported study, 12 patients with breast cancer were vaccinated with a subcutaneous priming dose of PANVAC-V followed by boosting doses of PANVAC-F.96 Four patients had stable disease and one patient achieved a complete response by RECIST, which has continued for 37 months. On the basis of findings that combining PANVAC with docetaxel has no effect on antigen-specific T-cell responses, a trial of docetaxel without and with PANVAC is being conducted for patients with metastatic breast cancer. ${ }^{97,98}$ of the 21 patients enrolled to date, the time to progression in the docetaxel-alone arm is 2.9 months (similar to previous studies) as compared with 8.0 months in the docetaxel + PANVAC arm. $^{99}$ This promising trial is currently underway at the National Cancer Institute and M.D. Anderson Cancer Center.

\section{Agents that directly target the MUC1-C CD}

As noted above, the MUC1-C CD contains a CQC motif that is necessary for its dimerization and oncogenic function. ${ }^{57}$ Accordingly, cell-penetrating peptides and small molecules have been developed that directly target the CQC motif and block MUC1-C dimerization in breast cancer cells. ${ }^{100,101}$ The first-in-class cell-penetrating MUC1-C peptide inhibitor, GO-201, binds directly to the MUC1-C CD at the CQC motif and attenuates localization of MUC1-C to the nucleus. ${ }^{100}$ GO-201 treatment was also associated with arrest of growth and induction of late apoptotic/necrotic cell death. Inhibition of MUC1-C dimerization affects interactions between MUC1-C and multiple effectors at the cell membrane and in the cytoplasm and nucleus. For example, GO-201 suppresses activation of the $\mathrm{Wnt} / \beta$-catenin pathway in breast cancer cells by blocking the interaction between MUC1-C and TCF7L2. ${ }^{73}$ Inhibition of MUC1-C also blocks its interaction with STAT3 and suppresses activation of the STAT3 pathway. ${ }^{21}$ Other studies have shown that GO-201 disrupts the interaction between MUC1-C and $N F-\kappa B$ RelA and decreases the expression of NF- $\kappa B$ target genes in breast cancer cells. ${ }^{20}$ Administration of GO-201 to immunocompromised mice bearing MCF-7 (ER+), ZR-75-1 $(E R+)$ and MDA-MB-231 (triple negative) breast tumor xenografts resulted in prolonged regressions, ${ }^{100}$ indicating that targeting MUC1-C could be a potential therapeutic approach in the clinic. On the basis of these findings and activity in other carcinoma models, ${ }^{102,38}$ a second-generation MUC1-C inhibitor, designated GO-203, has entered Phase I evaluation for patients with refractory solid tumors.

\section{CONCLUSIONS}

In summary, the overexpression of MUC1-C in breast cancers has been linked to the activation of several pathways that are known to be of importance to the development of breast cancer. The oncogenic function of MUC1-C is dependent, at least in large part, on its dimerization, which is mediated by the CQC motif in the CD. The development of agents that block MUC1-C dimerization has further demonstrated that MUC1-C is a druggable target. These findings have provided the experimental basis for targeting MUC1-C in patients with breast cancers who express this oncoprotein. Notably, in addition to breast cancer, MUC1-C is aberrantly overexpressed in diverse carcinomas, such as those derived from lung, ${ }^{38}$ prostate ${ }^{103}$ and other epithelial tissues. ${ }^{1}$ On the basis of the importance of MUC1-C to breast cancer as reviewed here, this oncoprotein may also contribute to the development of these other carcinomas and represent a target for their treatment.

\section{CONFLICT OF INTEREST}

Dr Kufe has ownership interest in Genus Oncology and is a consultant to the company.

\section{ACKNOWLEDGEMENTS}

This work has been supported by Grant CA97098 awarded by the National Cancer Institute.

\section{REFERENCES}

1 Kufe D. Mucins in cancer: function, prognosis and therapy. Nat Rev Cancer 2009; 9: $874-885$

2 Kufe D, Inghirami G, Abe M, Hayes D, Justi-Wheeler $H$, Schlom J. Differential reactivity of a novel monoclonal antibody (DF3) with human malignant versus benign breast tumors. Hybridoma 1984; 3: 223-232.

3 Ligtenberg MJ, Kruijshaar L, Buijs F, van Meijer M, Litvinov SV, Hilkens J. Cellassociated episialin is a complex containing two proteins derived from a common precursor. J Biol Chem 1992; 267: 6171-6177.

4 Levitin F, Stern O, Weiss M, Gil-Henn C, Ziv R, Prokocimer Z et al. The MUC1 SEA module is a self-cleaving domain. J Biol Chem 2005; 280: 33374-33386.

5 Macao B, Johansson DG, Hansson GC, Hard T. Autoproteolysis coupled to protein folding in the SEA domain of the membrane-bound MUC1 mucin. Nat Struct Mol Biol 2006; 13: 71-76.

6 Siddiqui J, Abe M, Hayes D, Shani E, Yunis E, Kufe D. Isolation and sequencing of a CDNA coding for the human DF3 breast carcinoma-associated antigen. Proc Natl Acad Sci USA 1988; 85: 2320-2323.

7 Gendler S, Taylor-Papadimitriou J, Duhig T, Rothbard J, Burchell JA. A highly immunogenic region of a human polymorphic epithelial mucin expressed by carcinomas is made up of tandem repeats. J Biol Chem 1988; 263: 12820-12823.

8 Abe M, Kufe D. Structural analysis of the DF3 human breast carcinoma associated protein. Cancer Res 1989; 49: 2834-2839.

9 Hayes DF, Sekine $H$, Ohno T, Abe M, Keefe K, Kufe DW. Use of a murine monoclonal antibody for detection of circulating DF3 antigen levels in breast cancer patients. J Clin Invest 1985; 75: 1671-1678.

10 Rakha EA, Boyce RW, Abd El-Rehim D, Kurien T, Green AR, Paish EC et al. Expression of mucins (MUC1, MUC2, MUC3, MUC4, MUC5AC and MUC6) and their prognostic significance in human breast cancer. Mod Pathol 2005; 18: 1295-1304.

11 Rahn JJ, Dabbagh L, Pasdar M, Hugh JC. The importance of MUC1 cellular localization in patients with breast carcinoma: an immunohistologic study of 71 patients and review of the literature. Cancer 2001; 91: 1973-1982.

12 McGuckin MA, Walsh MD, Hohn BG, Ward BG, Wright RG. Prognostic significance of MUC1 epithelial mucin expression in breast cancer. Hum Pathol 1995; 26: 432-439.

13 Merlo G, Siddiqui J, Cropp C, Liscia DS, Lidereau R, Callahan R et al. DF3 tumorassociated antigen gene is located in a region on chromosome 1q frequently altered in primary human breast cancer. Cancer Res 1989; 49: 6966-6971.

14 Bieche I, Lidereau R. A gene dosage effect is responsible for high overexpression of the MUC1 gene observed in human breast tumors. Cancer Genet Cytogenet 1997; 98: 75-80.

15 Lacunza E, Baudis M, Colussi AG, Segal-Eiras A, Croce MV, Abba MC. MUC1 oncogene amplification correlates with protein overexpression in invasive breast carcinoma cells. Cancer Genet Cytogenet 2010; 201: 102-110.

16 Abe M, Kufe D. Transcriptional regulation of the DF3 gene expression in human MCF-7 breast carcinoma cells. J Cell Physiol 1990; 143: 226-231.

17 Abe M, Kufe D. Characterization of cis-acting elements regulating transcription of the human DF3 breast carcinoma-associated antigen (MUC1) gene. Proc Natl Acad Sci USA 1993; 90: 282-286.

18 Kovarik A, Peat N, Wilson D, Gendler S, Taylor-Papadimitriou J. Analysis of the tissue-specific promoter of the MUC1 gene. J Biol Chem 1993; 268: 9917-9926.

19 Khodarev N, Ahmad R, Rajabi H, Pitroda S, Kufe T, McClary C et al. Cooperativity of the MUC1 oncoprotein and STAT1 pathway in poor prognosis human breast cancer. Oncogene 2010; 29: 920-929. 
20 Ahmad R, Raina D, Joshi MD, Kawano T, Kharbanda S, Kufe D. MUC1-C oncoprotein functions as a direct activator of the NF- $\mathrm{KB}$ p65 transcription factor. Cancer Res 2009; 69: 7013-7021.

21 Ahmad R, Rajabi H, Kosugi M, Joshi M, Alam M, Vasir B et al. MUC1-C oncoprotein promotes STAT3 activation in an auto-inductive regulatory loop. Sci Signal 2011; 4: ra9.

22 Rajabi H, Jin C, Ahmad R, McClary C, Kufe D. Mucin 1 oncoprotein expression is suppressed by the miR-125b oncomir. Genes \& Cancer 2010; 1: 62-65.

23 Sachdeva M, Mo YY. MicroRNA-145 suppresses cell invasion and metastasis by directly targeting mucin 1. Cancer Res 2010; 70: 378-387.

24 Jin C, Rajabi H, Kufe D. miR-1226 targets expression of the mucin 1 oncoprotein and induces cell death. Int J Oncol 2010; 37: 61-69.

25 Higgins MJ, Baselga J. Targeted therapies for breast cancer. J Clin Invest 2011; 121: 3797-3803.

26 Kufe D. Functional targeting of the MUC1 oncogene in human cancers. Cancer Biol Ther 2009; 8: 1201-1207.

27 Khodarev N, Pitroda S, Beckett M, MacDermed D, Huang L, Kufe D et al. MUC1induced transcriptional programs associated with tumorigenesis predict outcome in breast and lung cancer. Cancer Res 2009; 69: 2833-2837.

28 Pitroda S, Khodarev N, Beckett M, Kufe D, Weichselbaum R. MUC1-induced alterations in a lipid metabolic gene network predict response of human breast cancers to tamoxifen treatment. Proc Natl Acad Sci USA 2009; 106 5837-5841.

29 He C, Hobert M, Friend L, Carlin C. The epidermal growth factor receptor juxtamembrane domain has multiple basolateral plasma membrane localization determinants, including a dominant signal with a polyproline core. J Biol Chem 2002; 277: 38284-38293.

30 Vermeer PD, Einwalter LA, Moninger TO, Rokhlina T, Kern JA, Zabner J et al. Segregation of receptor and ligand regulates activation of epithelial growth factor receptor. Nature 2003; 422: 322-326.

31 Ramasamy S, Duraisamy S, Barbashov S, Kawano T, Kharbanda S, Kufe D. The MUC1 and galectin-3 oncoproteins function in a microRNA-dependent regulatory loop. Mol Cell 2007; 27: 992-1004.

32 Li Y, Ren J, Yu W, Li G, Kuwahara H, Yin L et al. The EGF receptor regulates interaction of the human DF3/MUC1 carcinoma antigen with c-Src and $\beta$-catenin. J Biol Chem 2001; 276: 35239-35242.

33 Li Y, Kuwahara H, Ren J, Wen G, Kufe D. The c-Src tyrosine kinase regulates signaling of the human DF3/MUC1 carcinoma-associated antigen with GSK3 $\beta$ and $\beta$-catenin. J Biol Chem 2001; 276: 6061-6064.

34 Schroeder J, Thompson M, Gardner M, Gendler S. Transgenic MUC1 interacts with epidermal growth factor receptor and correlates with mitogen-activated protein kinase activation in the mouse mammary gland. $J$ Biol Chem 2001; 276: 13057-13064.

35 Schroeder JA, Masri AA, Adriance MC, Tessier JC, Kotlarczyk KL, Thompson MC et al. MUC1 overexpression results in mammary gland tumorigenesis and prolonged alveolar differentiation. Oncogene 2004; 23: 5739-5747.

36 Pochampalli MR, Bitler BG, Schroeder JA. Transforming growth factor \{alpha\} dependent cancer progression is modulated by MUC1. Cancer Res 2007; 67: 6591-6598.

37 Merlin J, Stechly L, de Beauce S, Monte D, Leteurtre E, van Seuningen I et al. Galectin-3 regulates MUC1 and EGFR cellular distribution and EGFR downstream pathways in pancreatic cancer cells. Oncogene 2011; 30: 2514-2525.

38 Raina D, Kosugi M, Ahmad R, Panchamoorthy G, Rajabi H, Alam M et al. Dependence on the MUC1-C oncoprotein in non-small cell lung cancer cells. Mol Cancer Ther 2011; 10: 806-816.

39 Bitler BG, Goverdhan A, Schroeder JA. MUC1 regulates nuclear localization and function of the epidermal growth factor receptor. J Cell Sci 2010; 123: 1716-1723.

40 Li Y, Yu W-H, Ren J, Huang L, Kharbanda S, Loda M et al. Heregulin targets $\gamma$-catenin to the nucleolus by a mechanism dependent on the DF3/MUC1 protein. Mol Cancer Res 2003; 1: 765-775.

41 Ren J, Raina D, Chen W, Li G, Huang L, Kufe D. MUC1 oncoprotein functions in activation of fibroblast growth factor receptor signaling. Mol Cancer Res 2006; 4 873-883.

42 Singh PK, Behrens ME, Eggers JP, Cerny RL, Bailey JM, Shanmugam K et al. Phosphorylation of MUC1 by Met modulates interaction with p53 and MMP1 expression. J Biol Chem 2008; 283: 26985-26995.

43 Singh PK, Wen Y, Swanson BJ, Shanmugam K, Kazlauskas A, Cerny RL et al. Platelet-derived growth factor receptor beta-mediated phosphorylation of MUC1 enhances invasiveness in pancreatic adenocarcinoma cells. Cancer Res 2007; 67: 5201-5210.

44 Engelman JA. Targeting PI3K signalling in cancer: opportunities, challenges and limitations. Nat Rev Cancer 2009; 9: 550-562.

45 Liu P, Cheng H, Roberts TM, Zhao JJ. Targeting the phosphoinositide 3-kinase pathway in cancer. Nat Rev Drug Discov 2009; 8: 627-644.
46 Raina D, Kharbanda S, Kufe D. The MUC1 oncoprotein activates the anti-apoptotic PI3K/Akt and Bcl-xL pathways in rat 3Y1 fibroblasts. J Biol Chem 2004; 279: 20607-20612.

47 Horn G, Gaziel A, Wreschner DH, Smorodinsky NI, Ehrlich M. ERK and PI3K regulate different aspects of the epithelial to mesenchymal transition of mammary tumor cells induced by truncated MUC1. Exp Cell Res 2009; 315 1490-1504.

48 Kato K, Lu W, Kai H, Kim KC. Phosphoinositide 3-kinase is activated by MUC1 but not responsible for MUC1-induced suppression of Toll-like receptor 5 signaling Am J Physiol Lung Cell Mol Physiol 2007; 293: L686-L692.

49 Kosugi M, Ahmad R, Alam M, Uchida Y, Kufe D. MUC1-C oncoprotein regulates glycolysis and pyruvate kinase M2 activity in cancer cells. PLoS One 2011; 6: e28234.

50 Yao M, Zhang W, Zhang Q, Xing L, Xu A, Liu Q et al. Overexpression of MUC1 enhances proangiogenic activity of non-small-cell lung cancer cells through activation of Akt and extracellular signal-regulated kinase pathways. Lung 2011 189: $453-460$

51 Woo JK, Choi Y, Oh S-H, Jeong J-H, Choi D-H, Seo H-S et al. Mucin 1 enhances the tumor angiogenic response by activation of the AKT signaling pathway. Oncogene 2012; 31: 2187-2198.

52 Pandey P, Kharbanda S, Kufe D. Association of the DF3/MUC1 breast cancer antigen with Grb2 and the Sos/Ras exchange protein. Cancer Res 1995; 55 4000-4003.

53 Meerzaman D, Shapiro PS, Kim KC. Involvement of the MAP kinase ERK2 in MUC1 mucin signaling. Am J Physiol Lung Cell Mol Physiol 2001; 281: L86-L91.

54 Kinlough CL, Poland PA, Bruns JB, Harkleroad KL, Hughey RP. MUC1 membrane trafficking is modulated by multiple interactions. J Biol Chem 2004; 279: 53071-53077.

55 Kinlough CL, McMahan RJ, Poland PA, Bruns JB, Harkleroad KL, Stremple RJ et al Recycling of MUC1 is dependent on its palmitoylation. J Biol Chem 2006; 281: $12112-12122$

56 Liao HJ, Carpenter G. Role of the Sec61 translocon in EGF receptor trafficking to the nucleus and gene expression. Mol Biol Cell 2007; 18: 1064-1072.

57 Leng Y, Cao C, Ren J, Huang L, Chen D, Ito M et al. Nuclear import of the MUC1-C oncoprotein is mediated by nucleoporin Nup62. J Biol Chem 2007; 282 19321-19330

58 Raina D, Ahmad R, Rajabi H, Panchamoorthy G, Kharbanda S, Kufe D. Targeting cysteine-mediated dimerization of the MUC1-C oncoprotein in human cancer cells. Int J Oncol 2012; 40: 1643-1649.

59 Ren J, Agata N, Chen D, Li Y, Yu W-H, Huang L et al. Human MUC1 carcinomaassociated protein confers resistance to genotoxic anti-cancer agents. Cancer Cell 2004; 5: 163-175.

60 Ren J, Bharti A, Raina D, Chen W, Ahmad R, Kufe D. MUC1 oncoprotein is targeted to mitochondria by heregulin-induced activation of c-Src and the molecular chaperone HSP90. Oncogene 2006; 25: 20-31.

61 Polakis P. The many ways of Wnt in cancer. Curr Opin Genet Dev 2007; 17: 45-51.

62 Yamamoto M, Bharti A, Li Y, Kufe D. Interaction of the DF3/MUC1 breast carcinoma-associated antigen and $\beta$-catenin in cell adhesion. J Biol Chem 1997; 272: 12492-12494.

63 Li Y, Bharti A, Chen D, Gong J, Kufe D. Interaction of glycogen synthase kinase $3 \beta$ with the DF3/MUC1 carcinoma-associated antigen and $\beta$-catenin. Mol Cell Biol 1998; 18: 7216-7224.

64 Ren J, Li $Y$, Kufe $D$. Protein kinase $C \delta$ regulates function of the DF3/MUC1 carcinoma antigen in $\beta$-catenin signaling. J Biol Chem 2002; 277: 17616-17622.

65 Schroeder JA, Adriance MC, Thompson MC, Camenisch TD, Gendler SJ. MUC alters beta-catenin-dependent tumor formation and promotes cellular invasion. Oncogene 2003; 22: 1324-1332.

66 Li Y, Liu D, Chen D, Kharbanda S, Kufe D. Human DF3/MUC1 carcinoma-associated protein functions as an oncogene. Oncogene 2003; 22: 6107-6110.

67 Wen Y, Caffrey T, Wheelock M, Johnson K, Hollingsworth M. Nuclear association of the cytoplasmic tail of MUC1 and $\beta$-catenin. J Biol Chem 2003; 278: 38029-38039.

68 Huang L, Ren J, Chen D, Li Y, Kharbanda S, Kufe D. MUC1 cytoplasmic domain coactivates Wnt target gene transcription and confers transformation. Cancer Biol Ther 2003; 2: 702-706.

69 Huang L, Chen D, Liu D, Yin L, Kharbanda S, Kufe D. MUC1 oncoprotein blocks GSK3 $\beta$-mediated phosphorylation and degradation of $\beta$-catenin. Cancer Res 2005; 65: 10413-10422.

$70 \mathrm{Li} \mathrm{Y,} \mathrm{Yi} \mathrm{H,} \mathrm{Yao} \mathrm{Y,} \mathrm{Liao} \mathrm{X,} \mathrm{Xie} \mathrm{Y,} \mathrm{Yang} \mathrm{J} \mathrm{et} \mathrm{al.} \mathrm{The} \mathrm{cytoplasmic} \mathrm{domain} \mathrm{of} \mathrm{MUC1}$ induces hyperplasia in the mammary gland and correlates with nuclear accumulation of beta-catenin. PLoS One 2011; 6: e19102.

71 Hoppler S, Kavanagh CL. Wnt signalling: variety at the core. J Cell Sci 2007; 120 385-393.

72 MacDonald BT, Tamai K, He X. Wnt/beta-catenin signaling: components, mechanisms, and diseases. Dev Cell 2009; 17: 9-26. 
73 Rajabi H, Ahmad R, Jin C, Kosugi M, Alam M, Joshi M et al. MUC1-C Oncoprotein Induces TCF7L2 activation and promotes cyclin D1 expression in human breast cancer cells. J Biol Chem 2012 10703-10713.

74 Hatsell S, Rowlands T, Hiremath M, Cowin P. Beta-catenin and Tcfs in mammary development and cancer. J Mammary Gland Biol Neoplasia 2003; 8: 145-158.

75 Yu Q, Geng Y, Sicinski P. Specific protection against breast cancers by cyclin D1 ablation. Nature 2001; 411: 1017-1021.

76 Landis MW, Pawlyk BS, Li T, Sicinski P, Hinds PW. Cyclin D1-dependent kinase activity in murine development and mammary tumorigenesis. Cancer Cell 2006; 9: 13-22.

77 Dickson C, Fantl V, Gillett C, Brookes S, Bartek J, Smith R et al. Amplification of chromosome band 11q13 and a role for cyclin D1 in human breast cancer. Cancer Lett 1995; 90: 43-50.

78 Bartkova J, Lukas J, Muller H, Lutzhoft D, Strauss M, Bartek J. Cyclin D1 protein expression and function in human breast cancer. Int J Cancer 1994; 57: 353-361.

79 Gillett C, Fantl V, Smith R, Fisher C, Bartek J, Dickson C et al. Amplification and overexpression of cyclin D1 in breast cancer detected by immunohistochemical staining. Cancer Res 1994; 54: 1812-1817.

80 McIntosh GG, Anderson JJ, Milton I, Steward M, Parr AH, Thomas MD et al. Determination of the prognostic value of cyclin D1 overexpression in breast cancer. Oncogene 1995; 11: 885-891.

81 Lamb J, Ramaswamy S, Ford HL, Contreras B, Martinez RV, Kittrell FS et al. A mechanism of cyclin D1 action encoded in the patterns of gene expression in human cancer. Cell 2003; 114: 323-334.

82 Udhayakumar G, Jayanthi V, Devaraj N, Devaraj H. Interaction of MUC1 with beta-catenin modulates the Wnt target gene cyclinD1 in $\mathrm{H}$. pylori-induced gastric cancer. Mol Carcinog 2007; 46: 807-817.

$83 \mathrm{Yu} \mathrm{H}$, Pardoll D, Jove R. STATs in cancer inflammation and immunity: a leading role for STAT3. Nat Rev Cancer 2009; 9: 798-809.

$84 \mathrm{Yu} \mathrm{H}$, Jove R. The STATs of cancer-new molecular targets come of age. Nat Rev Cancer 2004; 4: 97-105.

85 Lagow EL, Carson DD. Synergistic stimulation of MUC1 expression in normal breast epithelia and breast cancer cells by interferon-gamma and tumor necrosis factor-alpha. J Cell Biochem 2002; 86: 759-772.

86 Gaemers IC, Vos HL, Volders HH, van der Valk SW, Hilkens JA. STAT-responsive element in the promoter of the episialin/MUC1 gene is involved in its overexpression in carcinoma cells. J Biol Chem 2001; 276: 6191-6199.

87 Kondo S, Yoshizaki T, Wakisaka N, Horikawa T, Murono S, Jang KL et al. MUC1 induced by Epstein-Barr virus latent membrane protein 1 causes dissociation of the cell-matrix interaction and cellular invasiveness via STAT signaling. J Virol 2007; 81: 1554-1562.

88 Hayden MS, Ghosh S. Shared principles in NF-кB signaling. Cell 2008; 132: 344-362.

89 Thompson EJ, Shanmugam K, Hattrup CL, Kotlarczyk KL, Gutierrez A, Bradley JM et al. Tyrosines in the MUC1 cytoplasmic tail modulate transcription via the extracellular signal-regulated kinase $1 / 2$ and nuclear factor-kappaB pathways. Mol Cancer Res 2006; 4: 489-497.

90 Ahmad R, Raina D, Trivedi V, Ren J, Rajabi H, Kharbanda S et al. MUC1 oncoprotein activates the $\mathrm{I} \mathrm{KB}$ kinase $\beta$ complex and constitutive NF- $\mathrm{KB}$ signaling. Nat Cell Biol 2007; 9: 1419-1427.

91 Zaretsky JZ, Barnea I, Aylon Y, Gorivodsky M, Wreschner DH, Keydar I. MUC1 gene overexpressed in breast cancer: structure and transcriptional activity of the MUC1 promoter and role of estrogen receptor alpha (ERalpha) in regulation of the MUC1 gene expression. Mol Cancer 2006; 5: 57.

92 Wei X, Xu H, Kufe D. MUC1 oncoprotein stabilizes and activates estrogen receptor $\alpha$. Mol Cell 2006; 21: 295-305.

93 Pegram MD, Borges VF, Ibrahim N, Fuloria J, Shapiro C, Perez S et al. Phase I dose escalation pharmacokinetic assessment of intravenous humanized anti-MUC1 antibody AS1402 in patients with advanced breast cancer. Breast Cancer Res 2009; 11: R73.

94 Ibrahim NK, Yariz KO, Bondarenko I, Manikhas A, Semiglazov V, Alyasova A et al. Randomized phase II trial of letrozole plus anti-MUC1 antibody AS1402 in hormone receptor-positive locally advanced or metastatic breast cancer. Clin Cancer Res 2011; 17: 6822-6830.

95 Gulley JL, Arlen PM, Tsang KY, Yokokawa J, Palena C, Poole DJ et al. Pilot study of vaccination with recombinant CEA-MUC-1-TRICOM poxviral-based vaccines in patients with metastatic carcinoma. Clin Cancer Res 2008; 14: 3060-3069.

96 Mohebtash M, Tsang KY, Madan RA, Huen NY, Poole DJ, Jochems C et al. A pilot study of MUC-1/CEA/TRICOM poxviral-based vaccine in patients with metastatic breast and ovarian cancer. Clin Cancer Res 2011; 17: 7164-7173.

97 Arlen PM, Pazdur M, Skarupa L, Rauckhorst M. Gulley JL. A randomized phase II study of docetaxel alone or in combination with PANVAC-V (vaccinia) and PANVAC-F (fowlpox) in patients with metastatic breast cancer ( $\mathrm{NCl} 05-\mathrm{C}-0229$ ). Clin Breast Cancer 2006; 7: 176-179.

98 Mohebtash M, Madan R, Gulley J, Jones J, Pazdur O, Heath M et al. Vaccine alone or with chemotherapy in patients with metastatic breast cancer (mBC). Am Soc Clin Oncol Breast Cancer Symp 2008; Abstract No: 163.

99 Gulley J, Heery C, Bilusic M, Kim J, Stadler W, DiPaola R et al. Combining vaccines with other therapeutics: a strategy to accelerate proof of concept studies? Soc Immunother Cancer 2011; Oral Presentation Abstracts, p. 56.

100 Raina D, Ahmad R, Joshi M, Yin L, Wu Z, Kawano T et al. Direct targeting of the MUC1 oncoprotein blocks survival and tumorigenicity of human breast carcinoma cells. Cancer Res 2009; 69: 5133-5141.

101 Zhou J, Rajabi H, Kufe D. MUC1-C oncoprotein is a target for small molecule inhibitors. Mol Pharm 2011; 79: 886-893.

102 Joshi MD, Ahmad R, Raina D, Rajabi H, Bubley G, Kharbanda S et al. MUC1 oncoprotein is a druggable target in human prostate cancer cells. Mol Cancer Ther 2009; 8: 3056-3065.

103 Rajabi H, Ahmad R, Jin C, Joshi MD, Guha M, Alam M et al. MUC1-C oncoprotein confers androgen-independent growth of human prostate cancer cells. Prostate 2012; 72: 1659-1668. 